\author{
V. Quisth · S. Enoksson · E. Blaak · E. Hagström-Toft · \\ P. Arner $\cdot$ J. Bolinder
}

\title{
Major differences in noradrenaline action on lipolysis and blood flow rates in skeletal muscle and adipose tissue in vivo
}

Received: 12 July 2004 / Accepted: 11 December 2004 / Published online: 19 March 2005

(C) Springer-Verlag 2005

\begin{abstract}
Aims/hypothesis: The regulation of skeletal muscle lipolysis is not fully understood. In the present study, the effects of systemic and local noradrenaline administration on lipolysis and blood flow rates in skeletal muscle and adipose tissue were studied in vivo. Methods: First, circulating noradrenaline levels were raised tenfold by a continuous i.v. infusion $(n=12)$. Glycerol levels (an index of lipolysis) were measured in $\mathrm{m}$. gastrocnemius and in abdominal adipose tissue using microdialysis. Local blood flow was determined with the ${ }^{133} \mathrm{Xe}$ clearance technique and whole-body lipolysis rates assessed with a stable glycerol isotope technique $\left(\left[{ }^{2} \mathrm{H}_{5}\right]\right.$ glycerol). Second, interstitial glycerol levels in $\mathrm{m}$. gastrocnemius, $\mathrm{m}$. vastus and adipose tissue were measured by microdialysis during local perfusion with noradrenaline $\left(10^{-8}-10^{-6} \mathrm{~mol} / \mathrm{l}\right)(n=10)$. Local blood flow was monitored with the ethanol perfusion technique. Results: With regard to systemic noradrenergic stimulation, no change in fractional release of glycerol (difference between tissue and arterial glycerol) was seen in skeletal muscle. In adipose tissue it transiently increased
\end{abstract}

V. Quisth · E. Hagström-Toft · P. Arner · J. Bolinder $(\triangle)$

Department of Medicine, M54,

Karolinska University Hospital,

Huddinge, Karolinska Institute,

14186 Stockholm, Sweden

e-mail: jan.bolinder@medhs.ki.se

Tel.: +46-8-58582361

Fax: $+46-8-58582407$

\section{S. Enoksson}

Department of Vascular Surgery,

Karolinska University Hospital, Huddinge,

Karolinska Institute,

Stockholm, Sweden

E. Blaak

Department of Human Biology,

Nutrition and Toxicology Research

Institute Maastricht, Maastricht University,

Maastricht, The Netherlands twofold ( $p<0.0001)$, and the rate of appearance of glycerol in plasma showed the same kinetic pattern. Blood flow was reduced by $40 \%$ in skeletal muscle $(p<0.005)$ and increased by $50 \%$ in adipose tissue $(p<0.05)$. After noradrenaline stimulation in situ, a discrete elevation of skeletal muscle glycerol was registered only at the highest concentration of noradrenaline $\left(10^{-6} \mathrm{~mol} / \mathrm{l}\right)(p<0.05)$. Adipose tissue glycerol doubled already at the lowest concentration $\left(10^{-8} \mathrm{~mol} / \mathrm{l}\right)$ $(p<0.05)$. In skeletal muscle a decrease in blood flow was seen at the highest noradrenaline concentrations $(p<0.05)$. Conclusions/interpretation: Lipolysis and blood flow rates are regulated differently in adipose tissue and skeletal muscle. Adipose tissue displays a high, but transient (tachyphylaxia) sensitivity to noradrenaline, leading to stimulation of both lipolysis and blood flow rates. In skeletal muscle, physiological concentrations of noradrenaline decrease blood flow but have no stimulatory effect on lipolysis rates.

Keywords Adipose tissue - Catecholamines - Glycerol . Lipolysis $\cdot$ Microdialysis $\cdot$ Skeletal muscle $\cdot{ }^{133} \mathrm{Xe}$ clearance

Abbreviations Glycerol $\mathrm{R}_{\mathrm{a}}$ : rate of appearance of glycerol

\section{Introduction}

Intracellular triglyceride stores are an important energy source in skeletal muscle. Non-esterified fatty acids, derived from intracellular triglycerides, are thought to contribute substantially to muscle energy requirements. Hence, during moderate exercise, intramuscular triglycerides account for up to $50 \%$ of NEFA oxidation [1]. On the other hand, excess of intramuscular triglyceride is associated with metabolic disorders such as type 2 diabetes and obesity, while muscle triglyceride content is closely related to skeletal muscle insulin resistance [2]. It is generally thought that reduced intramyocellular NEFA oxidation rather than the amount of muscle triglyceride in itself is 
important in insulin-resistant conditions [3]. It is not known whether this also includes abnormalities in the mobilisation of NEFA via hydrolysis of intramuscular triglyceride, i.e. skeletal muscle lipolysis.

While hormonal regulation of lipolysis in adipose tissue in humans is well characterised, less has been established about this process in skeletal muscle. In adipose tissue, hydrolysis of triglycerides is acutely stimulated by catecholamines and inhibited by insulin [4, 5]. Lipolysis in skeletal muscle appears to be regulated differently. Several studies have demonstrated that insulin does not suppress muscle lipolysis [6-8], which may be due to different phosphodiesterase subtypes in the two tissues [9]. With regard to the catecholamine regulation of skeletal muscle lipolysis, disparate findings have been reported. Local infusion of $\beta$-adrenergic agonists increases the lipolytic response in skeletal muscle [10]. In contrast, no effect on muscle lipolysis in vivo was registered in response to increased sympathetic nerve activity [11]. Local tissue blood flow may also be an important denominator of the lipolytic activity in adipose tissue both by affecting the delivery of hormones to the tissue as well as by controlling the release of glycerol of NEFA from the tissue [4], and may also play a role in skeletal muscle metabolism via similar mechanisms [12].

The aim of this study was therefore to further investigate the regulatory effects of catecholamines on skeletal muscle lipolysis and blood flow rates, and to compare the corresponding catecholamine actions in adipose tissue and on whole-body lipolysis rates.

\section{Subjects, materials and methods}

Subjects

On one or several occasions 17 healthy, drug-free volunteers (12 women and five men, $30 \pm 2$ years of age, BMI $23.0 \pm$ $0.8 \mathrm{~kg} / \mathrm{m}^{2}$ ) were studied. All of them performed regular physical activity but not at an athletic level. The Ethics Committee of the Karolinska Institute approved the study. The subjects were given a detailed description of the study before their informed consent was obtained.

\section{Microdialysis}

The microdialysis technique has been described in detail [13]. The microdialysis catheter (CMA/60; CMA Microdialysis, Stockholm, Sweden) with a semipermeable membrane $\left(30 \times 0.62 \mathrm{~mm}\right.$, molecular mass cut-off of $\left.20 \mathrm{M}_{\mathrm{r}}\right)$ was connected to a microinfusion pump (CMA/100 microinjection pump; CMA Microdialysis) and was continuously perfused with a sterile solution. An exchange of metabolites takes place over the microdialysis membrane and the composition of the outflow solution reflects the extracellular fluid.

\section{Study protocol}

All subjects were investigated in the supine position after an overnight fast. The experiments began at 07.30 hours.

Systemic noradrenaline administration $(n=12)$ A Teflon catheter (Venflon) was inserted in a dorsal hand vein. The hand was placed in a heated box $\left(63^{\circ} \mathrm{C}\right)$ for sampling of arterialised venous plasma. In the cubital vein of the contralateral arm a second Teflon catheter was placed for infusion of noradrenaline and $\left[{ }^{2} \mathrm{H}_{5}\right]$ glycerol. After superficial skin anaesthesia (Emla; Astra, Södertälje, Sweden) microdialysis catheters were inserted into the peri-umbilical subcutaneous adipose tissue and the medial part of the gastrocnemius muscle. The catheters were continuously perfused with Ringer's solution (Apoteksbolaget, Umeå, Sweden) containing $147 \mathrm{mmol} / 1 \mathrm{Na}, 4 \mathrm{mmol} / 1 \mathrm{~K}, 2.3 \mathrm{mmol} / \mathrm{l} \mathrm{Ca}$ and $156 \mathrm{mmol} / 1 \mathrm{Cl}$ at a flow rate of $0.3 \mu \mathrm{l} / \mathrm{min}$. This flow rate has previously been shown to result in almost complete recovery $(>95 \%)$ of glycerol in skeletal muscle and adipose tissue [14].

After an equilibration period of $120 \mathrm{~min}$, the dialysates were sampled throughout the experimental period in 15-min fractions for analysis of glycerol. An intravenous noradrenaline infusion $\left(0.56 \mathrm{nmol} \cdot \mathrm{kg}\right.$ lean body $\left.\operatorname{mass}^{-1} \cdot \mathrm{min}^{-1}\right)$ (Apoteksbolaget, Umeå, Sweden) was started after $60 \mathrm{~min}$ of basal sampling and continued for $75 \mathrm{~min}$. It has previously been shown that the circulating noradrenaline concentration increases up to the upper physiological level with this protocol [15]. The experiment was then completed by a 45-min recovery period. To estimate the total body lipolysis rate, a priming $(1.5 \mu \mathrm{mol} / \mathrm{kg})$ plus continuous $\left(0.1 \mu \mathrm{mol} \cdot \mathrm{kg}^{-1}\right.$. $\mathrm{min}^{-1}$ ) infusion of $\left[{ }^{2} \mathrm{H}_{5}\right]$ glycerol was given. The priming dose was given at $-120 \mathrm{~min}$ and the infusion then continued throughout the experiment.

To determine background isotopic enrichment, plasma samples were drawn at -130 and $-120 \mathrm{~min}$. Plasma samples for analysis of glycerol and $\left[{ }^{2} \mathrm{H}_{5}\right]$ glycerol were then drawn in the middle of each dialysate sampling period. The vials were immediately put on ice; plasma was separated within $30 \mathrm{~min}$ by cold centrifugation and thereafter stored at $-70^{\circ} \mathrm{C}$. The rate of appearance of glycerol (glycerol $\mathrm{R}_{\mathrm{a}}$; $\mu \mathrm{mol} \cdot \mathrm{kg}$ body weight ${ }^{-1} \cdot \mathrm{min}^{-1}$ ) was calculated by the equation: $F /$ (E plasma glycerol - E background), where $F$ denotes the infusion rate of $\left[{ }^{2} \mathrm{H}_{5}\right]$ glycerol $(\mu \mathrm{mol} \cdot \mathrm{kg}$ body weight ${ }^{-1} \cdot \mathrm{min}^{-1}$ ) and $\mathrm{E}$ plasma glycerol is the increase in the $\left[{ }^{2} \mathrm{H}\right]:\left[{ }^{1} \mathrm{H}\right]$ ratio of plasma glycerol during infusion (compared against background).

Concentrations of catecholamines (adrenaline and noradrenaline) and NEFA were determined at regular intervals during the procedure, as indicated in Results. Systolic and diastolic blood pressure and heart rate were measured every $15 \mathrm{~min}$, using an electronic oscillometric monitoring device (Omron 705 CP; Omron, Matsusaka, Japan).

Adipose tissue blood flow and skeletal muscle blood flow were determined with the ${ }^{133} \mathrm{Xe}$ clearance technique [16]. In adipose tissue, ${ }^{133} \mathrm{Xe}(1 \mathrm{MBq}$ in $0.1 \mathrm{ml}$ saline; Mallinckrodt, 
Petten, The Netherlands) was injected percutaneously into the para-umbilical subcutaneous tissue, opposite to the microdialysis catheter, $60 \mathrm{~min}$ before the noradrenaline infusion was started. After 30 min of equilibration, the residual activity was continuously monitored externally with a scintillation detector (Mediscint; Oakfields Instruments, Oxford, UK) throughout the study period. In skeletal muscle, the ${ }^{133} \mathrm{Xe}$ decay curve gradually becomes multiexponential and cannot be used for estimating muscle blood flow continuously over extended time periods. However, skeletal muscle blood flow can be correctly assessed from the initial part of the ${ }^{133} \mathrm{Xe}$ washout curve [17]. ${ }^{133} \mathrm{Xe}(0.3 \mathrm{MBq}$ in $0.1 \mathrm{ml}$ saline $)$ was therefore injected twice in the medial part of the contralateral gastrocnemius muscle. The first injection was made after $40 \mathrm{~min}$ of basal sampling and the second after $45 \mathrm{~min}$ of noradrenaline infusion. Recordings were started after $5 \mathrm{~min}$ of equilibration, and continued for $10 \mathrm{~min}$. Adipose tissue and muscle blood flow were calculated according to the formula $\mathrm{TBF}=k \times \lambda \times 100\left(\mathrm{ml}-100 \mathrm{~g}^{-1} \cdot \mathrm{min}^{-1}\right)$, where TBF denotes tissue blood flow, $k$ denotes the rate constant of the decay of the residual activity and $\lambda$ the tissue-to-blood partition coefficient. The values for $\lambda$ were set at $10 \mathrm{ml} / \mathrm{g}$ for adipose tissue and $0.7 \mathrm{ml} / \mathrm{g}$ for muscle $[16,18]$.

Noradrenaline administration in situ In separate experiments $(n=10)$ local stimulation by noradrenaline was studied in adipose tissue and two different muscle groups. Microdialysis catheters were inserted into the abdominal subcutaneous tissue, the mid-part of the vastus lateralis muscle and the medial part of the gastrocnemius muscle, and continuously perfused with Ringer's solution, as described before. In the experiments, the dialysate samples for analysis of glycerol were collected in 15-min fractions. After a baseline period of $60 \mathrm{~min}$, noradrenaline was added to the perfusate of the microdialysis catheters. The initial concentration was $10^{-8} \mathrm{~mol} / \mathrm{l}$. After $60 \mathrm{~min}$ the noradrenaline concentration was increased to $10^{-7} \mathrm{~mol} / \mathrm{l}$, and over the last $60 \mathrm{~min}$ to $10^{-6} \mathrm{~mol} / 1$.

In these experiments, the previously used perfusate flow rate of $0.3 \mu \mathrm{l} / \mathrm{min}$ could not be used because the absolute recovery (total amount of a substance passing the microdialysis membrane over a defined time period), and thereby the rates of noradrenaline administration to the tissues were too low. On the other hand, when faster microdialysis flow rates are used to increase the absolute recovery, it is essential to ensure that the delivery of the substance administered via the microdialysis catheter, as well as the relation between the concentration of the metabolite of interest in the sampled microdialysate vs the true tissue interstitial concentration (i.e. the relative recovery), are comparable in both adipose tissue and muscle. Therefore, the concentration of urea in the dialysates from the two tissues was used as reference of the relative recovery in the tissues [19]. The concentration of urea is considered to be the same in the extracellular fluid in all body tissues. The urea concentration in the dialysates was measured during the end of the equilibration period in the adipose tissue and the muscle groups. In uncharted methodological experiments different perfusate flow velocities were tested in adipose tissue and muscle. These experiments showed that, using a flow rate of $2.0 \mu \mathrm{l} / \mathrm{min}$ in adipose tissue and $5 \mu \mathrm{l} / \mathrm{min}$ in the skeletal muscle, corresponding relative recoveries of urea were obtained in the two tissues. Therefore, these respective flow rates were used in the study.

To estimate variations in tissue blood flow, ethanol was added to the perfusate solution as a flow marker [20]. Ethanol is not locally degraded, and does not affect tissue metabolism. Hence, changes in the ethanol concentration ratio (outvs in-going ethanol concentration) reflect changes in the local blood flow.

\section{Biochemical analysis}

Dialysate glycerol was measured with an enzymatic fluorometric method with an automatic tissue dialysate sample analyser (CMA/600). Dialysate ethanol was determined with an enzymatic spectrophotometric method [21]. Plasma glycerol was determined by bioluminescence [22]. Plasma catecholamines were measured with high-performance chromatography with electrochemical detection [23]. NEFA in serum were analysed with an enzymatic colorimetric method (Wako Chemicals, Neuss, Germany). To determine isotopic enrichment of $\left[{ }^{2} \mathrm{H}_{5}\right]$ glycerol, glycerol was derivatised to a heptafluobutyric acid anhydrate derivate. Isotopic enrichment was determined by gas chromatography-mass spectrometry (Finnigan Automass, Bremen, Germany) [24].

\section{Statistics}

Data are presented as means \pm SEM. Variations over time in the same individual were evaluated with one-factor ANOVA, corrected for repeated measurements. Comparisons over time between groups were analysed with two-factor repeated measurement ANOVA. Factorial ANOVA was used for comparison between groups not involving time. Post-hoc analyses were performed by Scheffe's F-test. Student's paired $t$-test was also used when different time segments were compared. A value of $p<0.05$ was considered statistically significant.

\section{Results}

Systemic noradrenergic stimulation Plasma noradrenaline was $1.0 \pm 0.1 \mathrm{nmol} / 1$ during basal sampling. Immediately after the onset of the i.v. noradrenaline infusion, the circulating concentration of noradrenaline increased about tenfold, and reached a plateau that lasted throughout the infusion (Fig. 1a). When the noradrenaline infusion was stopped, plasma noradrenaline rapidly decreased towards basal values during the recovery period (Fig. 1a). The concentrations of adrenaline in plasma were below the detection limit of this method $(0.3 \mathrm{nmol} / \mathrm{l})$ for the majority of the subjects throughout the study procedure. The increases in circulating noradrenaline levels were paralleled by a sustained elevation of approximately 20 and $5-10 \mathrm{mmHg}$ 
a

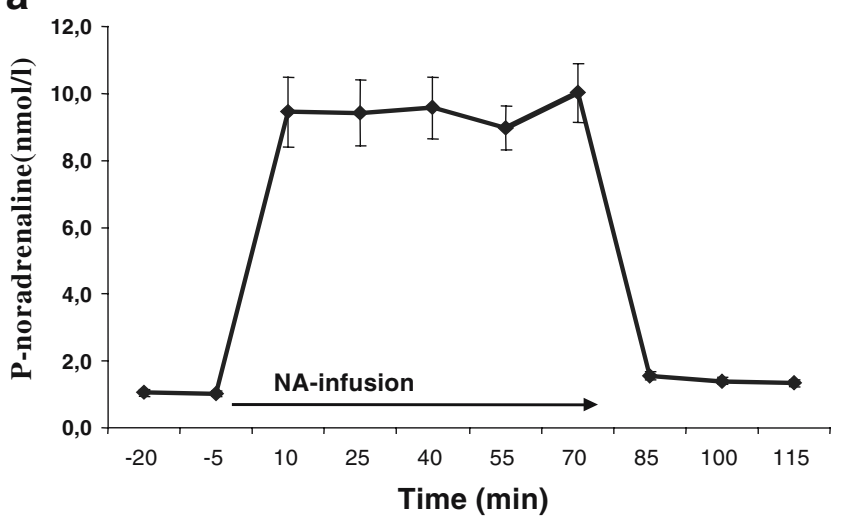

b
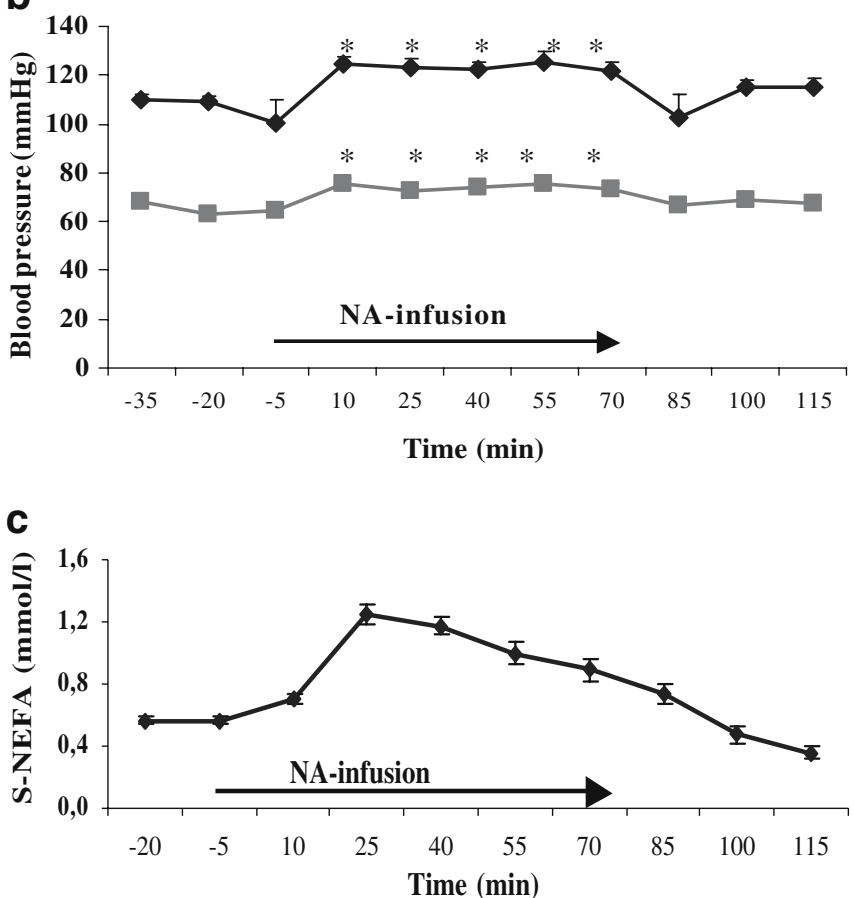

Fig. 1 Effect of systemic noradrenaline infusion on arterialised venous plasma $(P)$ noradrenaline $(\mathbf{a})$, blood pressure $(\mathbf{b})$ and serum $(S)$ NEFA (c) in 12 healthy subjects. Values are means \pm SEM. a Rhomboids P-noradrenaline concentration; b rhomboids systolic blood pressure, squares diastolic blood pressure; c rhomboids S-NEFA, $* p<0.05$

$(p<0.002$, ANOVA $)$ in systolic and diastolic blood pressure respectively (Fig. 1b). The heart rate decreased transiently from a basal value of $63 \pm 2$ to $51 \pm 8$ beats $/ \min (p<0.01)$ at $15 \mathrm{~min}$ after the onset of the i.v. noradrenaline infusion, but thereafter it reverted to basal rates. Serum NEFA are shown in Fig. 1c. The concentration of NEFA in serum increased markedly in response to the noradrenaline infusion and peaked at approximately twice the basal levels after $25 \mathrm{~min}$. It then gradually decreased as the noradrenaline infusion continued, to reach values below initial levels at the end of the recovery period.

The glycerol concentrations in plasma, adipose tissue and skeletal muscle are shown in Fig. 2a. In the basal state, the glycerol levels were approximately $50 \%$ higher in the muscle tissue than in plasma ( $p<0.05$, factorial ANOVA). The adipose tissue glycerol concentration was three to four times higher than in plasma and skeletal muscle tissue $(p<0.0001$ by factorial ANOVA). There were significant increases in plasma, adipose tissue and muscle tissue glycerol in response to the noradrenaline infusion $(p<0.0001$ by one-factor ANOVA for repeated measurements in each compartment). The elevated concentrations were seen immediately after the infusion was started and peaked at $25 \mathrm{~min}$ in plasma and adipose tissue. In $\mathrm{m}$. gastrocnemius the maximum peak was seen after $40 \mathrm{~min}$. In each compartment, the peak glycerol values were about twice the respective basal

a
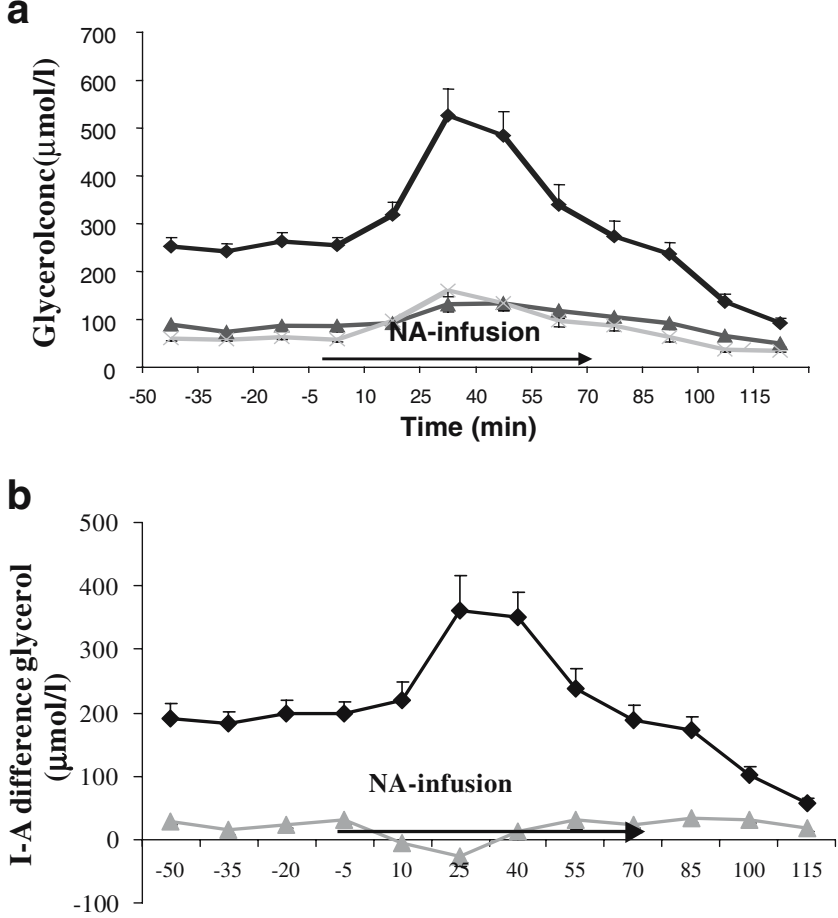

Time (min)

C

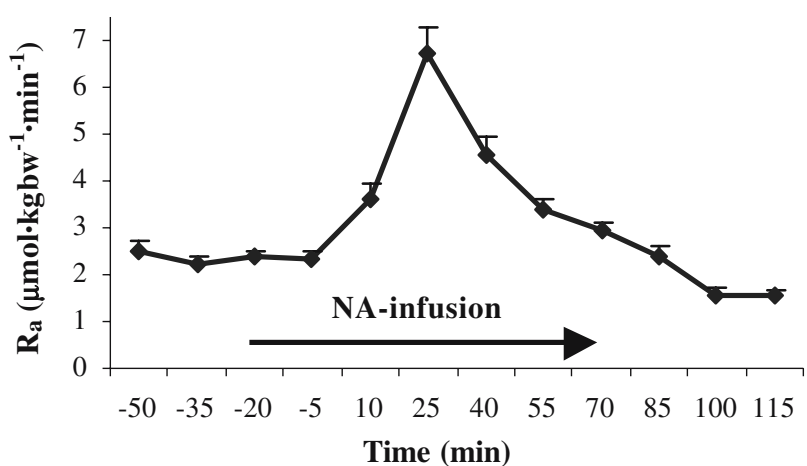

Fig. 2 Effect of i.v. noradrenaline infusion on (a) glycerol in arterialised venous plasma (cross), adipose tissue (rhomboid) and $\mathrm{m}$. gastrocnemius (triangle); b the difference between the interstitial tissue glycerol concentration and the arterialised venous plasma glycerol level (I-A difference) (rhomboids I-A difference in adipose tissue, triangles I-A difference in skeletal muscle); and (c) the rate of whole-body appearance of glycerol, as assessed during system infusion of $\left[{ }^{2} \mathrm{H}_{5}\right]$ glycerol (rhomboids rate of appearance $\left[\mathrm{R}_{\mathrm{a}}\right]$ of whole-body glycerol). Values are means \pm SEM 
values. The glycerol levels then gradually decreased and towards the end of the recovery period they were below basal levels in all three compartments.

Figure $2 b$ depicts the fractional release of glycerol, i.e. the difference between the interstitial glycerol concentration in adipose and muscle tissue respectively, and the glycerol concentration in arterialised venous plasma. In adipose tissue, noradrenaline stimulation gave a significant increase of the interstitial-plasma difference in glycerol $(p<0.0001$ one-factor ANOVA, repeated measurements). The fractional glycerol release followed the same pattern as the absolute glycerol curve in adipose tissue. The values for the difference between the interstitial tissue glycerol concentration and the arterialised venous plasma glycerol level were doubled after $25 \mathrm{~min}$ of the noradrenaline infusion and then declined to less than basal levels at the end of the experiment. In skeletal muscle, there was no significant change in the fractional release of glycerol during the experimental period.

The glycerol $R_{a}$ is shown in Fig. 2c. The glycerol $R_{a}$ curve was almost identical with the curve for fractional glycerol release in adipose tissue. There was an immediate increase in glycerol $\mathrm{R}_{\mathrm{a}}$ when the noradrenaline infusion started and the peak was seen after $25 \min (p<0.0001$, one-way ANOVA, repeated measurements). Glycerol $\mathrm{R}_{\mathrm{a}}$ then gradually decreased as the noradrenaline infusion continued, reaching values slightly lower than basal levels during the recovery period.

a

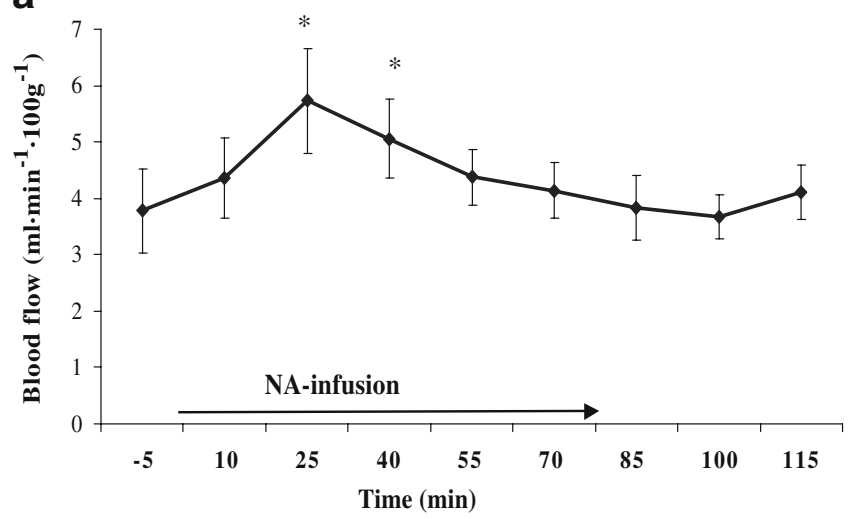

b

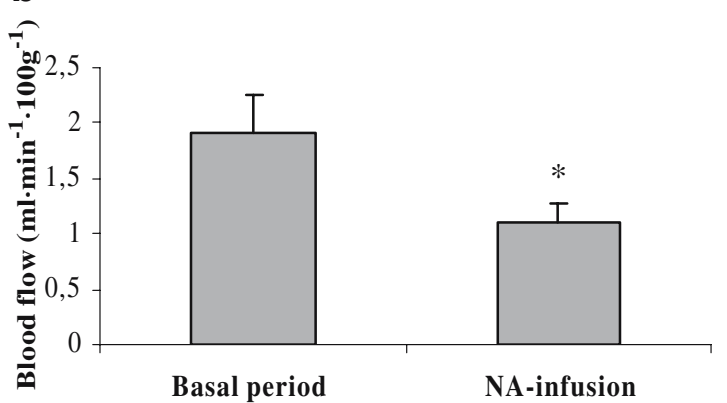

Fig. 3 Effect of systemic noradrenaline stimulation on local blood flow in adipose tissue (a) and $\mathrm{m}$. gastrocnemius (b). Values are means \pm SEM. ${ }^{*} p<0.005$ for comparison of blood flow in skeletal muscle during basal period vs noradrenaline infusion (Student's paired $t$-test)
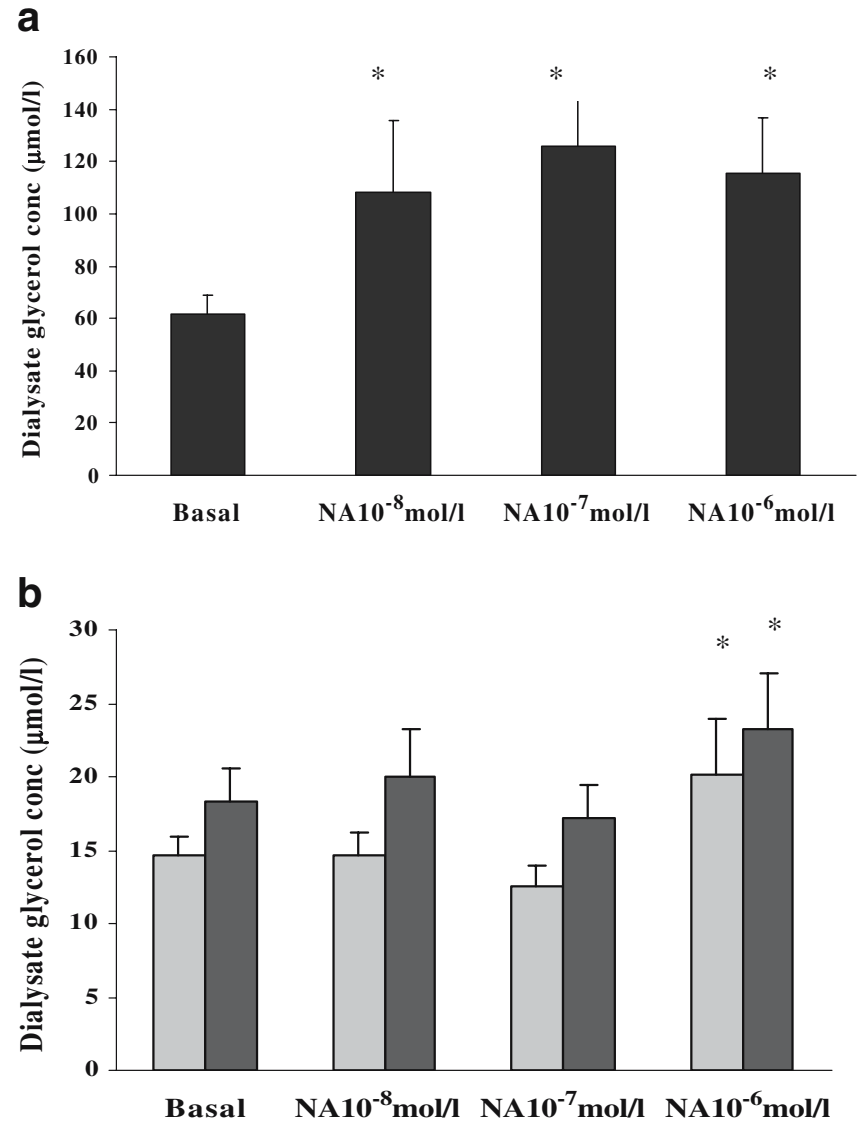

Fig. 4 Effect of increasing concentrations of noradrenaline in situ on glycerol in (a) adipose tissue and (b) m. gastrocnemius (dark bars) and $\mathrm{m}$. vastus lateralis (light bars). Statistical differences between noradrenaline concentrations were calculated with one-way ANOVA for repeated measurements and post-hoc analysis Scheffe's $F$-test. $N A$ Noradrenaline. ${ }^{*} p<0.05$ for differences between noradrenaline concentrations

The local blood flow rates in adipose tissue and skeletal muscle are shown in Fig. 3. In the basal state, the blood flow rates in adipose tissue were twice those in $\mathrm{m}$. gastrocnemius. In adipose tissue a significant rise in blood flow rates was seen $(p<0.05$, one-factor ANOVA for repeated measurements) (Fig. 3a). The elevated flow rates in adipose tissue started immediately after the onset of the noradrenaline infusion and peaked after $25 \mathrm{~min}$. They then gradually decreased to basal levels. In skeletal muscle the blood flow rates were reduced by approximately $40 \%$ during noradrenaline stimulation ( $p<0.005$, Student's $t$-test) (Fig. 3b).

Noradrenaline stimulation in situ There was no significant difference in dialysate urea concentrations: $2.1 \pm 0.4 \mathrm{mmol} / 1$ in adipose tissue, $1.7 \pm 0.1 \mathrm{mmol} / \mathrm{l} \mathrm{in} \mathrm{m}$. vastus lateralis and $1.7 \pm 0.1 \mathrm{mmol} / \mathrm{l} \mathrm{in} \mathrm{m}$. gastrocnemius respectively, during the last $60 \mathrm{~min}$ of equilibration. The ratio between the dialysate urea concentration and the urea concentration in arterialised venous plasma $\times 100 \%$ (i.e. the relative recovery) was $39.5 \pm$ $6.8 \%$ in adipose tissue, $32.3 \pm 2.0 \%$ in $\mathrm{m}$. vastus lateralis, and $32.7 \pm 1.5 \%$ in $\mathrm{m}$. gastrocnemius respectively ( $p=\mathrm{NS}$ ).

In the basal state, the glycerol levels in adipose tissue were three times higher than in $\mathrm{m}$. gastrocnemius and four 


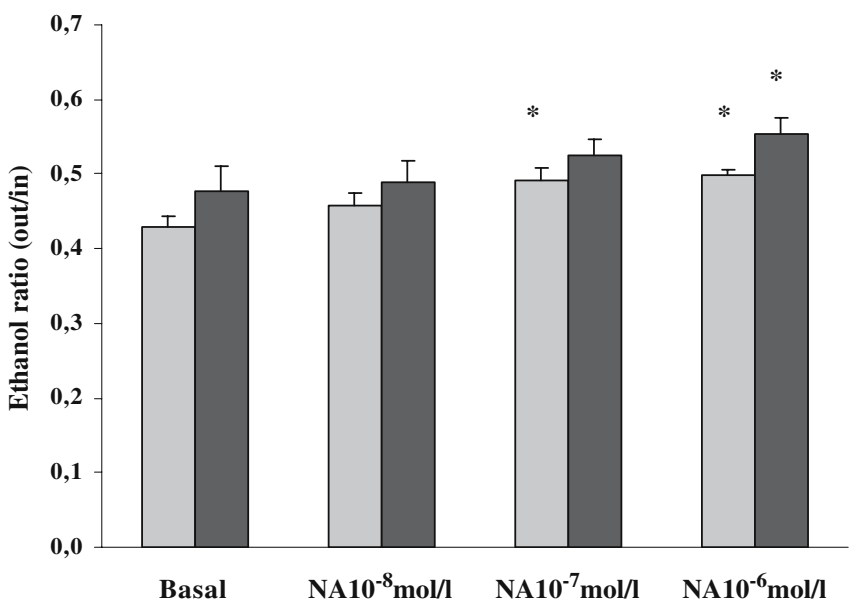

Fig. 5 Effect of increasing concentrations of noradrenaline in situ on variations in blood flow assessed by ethanol outflow:inflow ratio in $\mathrm{m}$. vastus lateralis (light bars) and $\mathrm{m}$. gastrocnemius (darks bars). Statistical differences between noradrenaline concentrations were calculated with one-way ANOVA for repeated measurements and post-hoc analysis Scheffe's $F$-test. ${ }^{*} p<0.05$ for differences between noradrenaline concentrations

times higher than in $\mathrm{m}$. vastus lateralis. Basal tissue glycerol was significantly higher in $\mathrm{m}$. gastrocnemius than in $\mathrm{m}$. vastus lateralis $(p<0.01$, factorial ANOVA). In response to noradrenaline, glycerol in adipose tissue was significantly increased ( $p<0.05$, one-way ANOVA for repeated measurements) even at the lowest concentration of noradrenaline $\left(10^{-8} \mathrm{~mol} / \mathrm{l}\right)$, with no further rise seen at the higher noradrenaline concentrations (Fig. 4a). In the two skeletal muscle tissues, a discrete but statistically significant elevation in the glycerol values was seen only at the highest concentration of noradrenaline tested $\left(10^{-6} \mathrm{~mol} / \mathrm{l}\right)(p<0.05$, by one-way ANOVA for repeated measurements) (Fig. 4b).

The ethanol outflow:inflow ratio was significantly increased at $10^{-7} \mathrm{~mol} / \mathrm{l}$ of noradrenaline in $\mathrm{m}$. vastus lateralis $(p<0.05$, one-factor ANOVA for repeated measurements), indicating a decrease in blood flow rates. In $\mathrm{m}$. gastrocnemius a significant increase was seen at the highest $\left(10^{-6} \mathrm{~mol} / \mathrm{l}\right)$ noradrenaline concentration (Fig. 5).

\section{Discussion}

This study demonstrated markedly different regulatory roles of noradrenaline in skeletal muscle and adipose tissue lipolysis and blood flow rates in vivo. In the first type of experiment, triglyceride hydrolysis was investigated using microdialysate measures of interstitial glycerol when noradrenaline was delivered systemically by an intravenous infusion. To consider different adipose masses in the subjects, the noradrenaline doses were calculated according to lean body mass. The noradrenaline concentration in plasma almost immediately reached a steady level of approximately ten times higher than the basal concentration, which was maintained throughout the $75-\mathrm{min}$ infusion period. The central haemodynamic responses (i.e. sustained elevation of blood pressure and transient decrease in heart rate) were in keeping with previous reports $[15,25]$. Moreover, as expected, a pronounced rise in interstitial glycerol was seen in adipose tissue in response to the noradrenaline infusion. However, during the second half of the infusion the glycerol levels continuously decreased towards basal levels. In agreement with previous findings [26, 27], this phenomenon is best explained by catecholamine tachyphylaxia, i.e. desensitisation of the beta-adrenergic receptors in response to sustained [26] or repeated [27] catecholamine stimulation.

The fractional release of glycerol in the adipose tissue, the difference between the interstitial and the arterialised venous plasma glycerol concentration, as well as the concentration of NEFA in arterialised venous plasma followed the same pattern as interstitial glycerol in adipose tissue. $\left[{ }^{2} \mathrm{H}_{5}\right]$ glycerol was infused systemically to estimate total body lipolysis and showed the same kinetic pattern in response to noradrenaline. Considered together, these findings underline adipose tissue as the dominating contributor to total body lipolysis during systemic exposure to noradrenaline.

In skeletal muscle, on the other hand, the noradrenaline infusion had no appreciable effect on lipolytic activity. The interstitial glycerol levels in the muscle tissue increased, indicating stimulation of lipolysis. However, when the inflow of glycerol via the circulation from other tissues (i.e. adipose tissue) was considered by calculating the fractional skeletal muscle glycerol release, no stimulation by noradrenaline was evident. The elevation of interstitial glycerol in muscle was also delayed in time in comparison with that in adipose tissue, which further implies that the rise in muscle glycerol mainly originated from increased inflow of glycerol from adipose tissue.

Variations in local blood flow rates may also influence lipolytic activity and tissue glycerol levels [4, 12, 28]. Previous studies on the effects of noradrenaline on the nutritive blood flow in adipose tissue and skeletal muscle are limited. Studies where the ${ }^{133} \mathrm{Xe}$ clearance methods have been used in adipose tissue and plethysmography in skeletal muscle have given divergent results. Vasoconstriction in both adipose tissue and muscle tissue, as well as vasodilatation in adipose tissue coupled with no vascular reaction in the muscle, has been described [25, 29]. Dose-related blood flow responses to noradrenaline in skeletal muscle have been registered using forearm plethysmography. Low doses of noradrenaline increased the local blood flow, while the muscle was indifferent to high doses of noradrenaline [30]. In a recent study, the nutritive blood flow remained unaltered in adipose tissue and in skeletal muscle when sympathetic nerve activity was induced via lower body negative pressure [11]. In the present study, the local blood flow was measured using ${ }^{133} \mathrm{Xe}$ clearance techniques in the first type of experiment. This technique allows a continuous registration of blood flow in adipose tissue, where a marked increase followed by a successive decline in the nutritive blood flow rates was observed. The diminishing stimulatory effect on blood flow rates during the continuous noradrenaline infusion indicates tachyphylaxia also in the vascular bed in response to noradrenaline in the adipose tissue. Thus, we cannot rule out with certainty that the transient noradrena- 
line-induced increase in adipose tissue lipolysis rates was influenced by waning delivery of the catecholamine via the circulation, rather than being a reflection of adipocyte betaadrenoceptor desensitisation. However, the fact that repeated administration of noradrenaline to adipose tissue in situ resulted in a blunted lipolytic response but with no appreciable effect on blood flow rates [27], renders this possibility less likely. Further insight into this issue might be given by monitoring the interstitial concentrations of noradrenaline. Unfortunately, at present, it is not possible to accomplish measurements of the absolute concentration of the catecholamine using microdialysis.

In the skeletal muscle, the blood flow measurements were limited to one before and one during the noradrenaline infusion. This is because the ${ }^{133} \mathrm{Xe}$ degradation curve becomes multiexponential over time in skeletal muscle [18]. Our findings indicated a decrease in skeletal muscle blood flow during noradrenaline exposure. The observed lower blood flow rate might have been preceded by even lower blood flow rates, since we cannot with certainty rule out the possibility that catecholamine tachyphylaxia also occurs in the vessels of the muscle tissue. As reviewed by Clark et al. [31], the vascular effects of noradrenaline may also include site-specific vasoconstriction and functional shunting of blood flow in skeletal muscle. Thus, it might again be argued that the observed lack of noradrenaline-induced stimulation of skeletal muscle lipolysis was obscured by vascular events, leading to diminished delivery and exposure of the myocytes to the catecholamine. However, the finding that interstitial glycerol levels increased significantly, owing to enhanced arterial inflow of glycerol, as well as the results of the in situ noradrenaline perfusion experiments (see below), speak against this notion.

In the second study protocol, the tissues were exposed to noradrenaline in situ. To ensure sufficient delivery of noradrenaline to the tissues, the perfusate flow rates had to be increased. However, when higher flow rates are used it is necessary to calibrate for possible differences in relative microdialysis recovery in adipose tissue and skeletal muscle. To ensure comparable relative recovery rates in the two tissue compartments, and hence similar rates of noradrenaline administration, urea was used as a reference [19]. By using perfusion flow rates of $2.0 \mu \mathrm{l} / \mathrm{min}$ in adipose tissue and $5.0 \mu \mathrm{l} / \mathrm{min}$ in skeletal muscle the same recovery of urea was ascertained in the two tissues. Comparable relative recoveries were also indicated by the relation of glycerol in adipose tissue versus that in skeletal muscle during basal recordings, which was the same in the in situ perfusion experiments as in the first experimental protocol where true, absolute tissue concentrations of glycerol were measured.

Tissue glycerol increased markedly even when the adipose tissue was exposed to the lowest noradrenaline concentration tested $\left(10^{-8} \mathrm{~mol} / \mathrm{l}\right)$. By contrast, in the skeletal muscle a slight elevation of the glycerol concentrations was registered only at the highest noradrenaline concentration $\left(10^{-6} \mathrm{~mol} / \mathrm{l}\right)$ tested. Hence, the sensitivity of lipolysis to noradrenaline stimulation appears to be at least 100 times higher in adipose tissue than in skeletal muscles in humans. Changes in skeletal muscle blood flow were estimated with the ethanol outflow: inflow in ratio, and a decrease in muscle blood flow was also seen at the highest noradrenaline concentration. It should be noted, however, that the microdialysis-ethanol method can only delineate major changes $(>50 \%)$ in blood flow rates [20]. Therefore, we may have missed a subtle, but significant, effect on blood flow rates at lower concentrations of noradrenaline. Thus, the observed rise in muscle tissue glycerol may have been the result of a noradrenaline-mediated reduction in the local blood flow rather than of a stimulation of lipolytic activity [28]. At any rate, if noradrenaline possesses a stimulatory effect on skeletal muscle lipolysis, this seems to be a pharmacological rather than a physiological action of the hormone. This may seem at odds with our previous report that local stimulation of the $\beta_{2}$-adrenoreceptor agonist terbutaline markedly increased lipolysis and local blood flow rates in skeletal muscle [10]. Notably, however, the $\beta_{2}$-adrenoreceptor, which predominates in skeletal muscle, has greater affinity for adrenaline than for noradrenaline [32, 33]. Thus, it is possible that lipolysis in skeletal muscle tissue is more sensitive to adrenaline stimulation via the $\beta_{2}$-adrenoreceptor during physiological conditions.

We have also previously shown that lipolytic activity varies among different muscle groups, possibly correlated to composition of fibre types [34]. Accordingly, muscles with dominating type 1 fibres are more oxidative and show greater hormone-sensitive lipase activity than type 2 fibre containing glycolytic muscles [35]. We also demonstrated in this study higher basal lipolysis rates in $\mathrm{m}$. gastrocnemius than in $\mathrm{m}$. vastus lateralis. M. gastrocnemius has a larger content of type 1 fibres and is more prone to NEFA oxidation, and consequently ought to be a muscle with high sensitivity to lipolytic agents. However, no difference in the lipolytic response to noradrenaline between the muscle groups was registered.

In conclusion, the regulation of glycerol release in response to noradrenaline stimulation is complex in adipose tissue and muscle involving both metabolic and vascular factors. However, in adipose tissue the sensitivity to noradrenaline is markedly higher than in skeletal muscle, leading to marked although transient increases in lipolysis and blood flow rates. In skeletal muscle, on the other hand, high physiological concentrations of noradrenaline decrease local blood flow, but have no apparent influence on the lipolytic activity.

Acknowledgements This study was supported by grants from the Swedish Research Council, the Swedish Diabetes Association and the Karolinska Institute. We acknowledge the excellent technical assistance of B.-M. Leijonhufvud, K. Hertel, E. Sjölin, and K. Wåhlén.

\section{References}

1. Guo Z, Burguera B, Jensen MD (2000) Kinetics of intramuscular fatty acids in exercising humans. J Appl Physiol 89:20572064

2. Kelley DE, Goodpasture BH (2001) Skeletal muscle triglyceride. An aspect of regional adiposity and insulin resistance. Diabetes Care 24:933-941

3. McGarry JD (2002) Dysregulation of fatty acid metabolism in the etiology of type 2 diabetes. Diabetes 51:7-17 
4. Arner P (1996) Regulation of lipolysis in fat cells. Diabetes Rev 4:450-463

5. Coppack SW, Jensen MD, Miles JM (1994) In vivo regulation of lipolysis in humans. J Lipid Res 35:177-193

6. Bolinder J, Kerckhoffs DA, Moberg E, Hagström-Toft E, Arner P (2000) Rates of skeletal muscle and adipose tissue glycerol release in nonobese and obese subjects. Diabetes 49:797-802

7. Moberg E, Sjöberg S, Hagström-Toft E, Bolinder J (2002) No apparent suppression by insulin of in vivo skeletal muscle lipolysis in nonobese women. Am J Physiol Endocrinol Metab 283:E295-E301

8. Sjöstrand M, Gudbjörnsdottir S, Holmäng A, Strindberg L, Ekberg K, Lönnroth P (2002) Measurements of interstitial muscle glycerol in normal and insulin-resistant subjects. J Clin Endocrinol Metab 87:2206-2211

9. Enoksson S, Degerman E, Hagström-Toft E, Large V, Arner P (1998) Various phosphodiesterase subtypes mediate in vivo antilipolytic effect of insulin on adipose tissue and skeletal muscle in man. Diabetologia 41:560-568

10. Hagström-Toft E, Enoksson S, Moberg E, Bolinder J, Arner P (1998) $\beta$-Adrenergic regulation of lipolysis and blood flow in human skeletal muscle in vivo. Am J Physiol 275:E909-E916

11. Navegantes LCC, Sjöstrand M, Gudbjörnsdottir S, Strindberg L, Elam M, Lönnroth P (2003) Regulation and counterregulation of lipolysis in vivo: different roles of sympathetic activation and insulin. J Clin Endocrinol Metab 88:5515-5520

12. Delp MD, Laughlin MH (1998) Regulation of skeletal muscle perfusion during exercise. Acta Physiol Scand 162:411-419

13. Tossman U, Ungerstedt U (1986) Microdialysis in the study of extracellular levels of amino acids in the rat brain. Acta Physiol Scand 128:9-14

14. Hagström-Toft E, Enoksson S, Moberg E, Bolinder J, Arner P (1997) Absolute concentrations of glycerol and lactate in human skeletal muscle, adipose tissue and blood. Am J Physiol Endocrinol Metab 273:E585-E592

15. Kurpad A, Khan H, Calder AG et al (1994) Effect of noradrenaline on glycerol turnover and lipolysis in the whole body and subcutaneous adipose tissue in humans in vivo. Clin Sci 86:177184

16. Larsen OA, Lassen NA, Quaade F (1966) Blood flow through human adipose tissue determined with radioactive xenon. Acta Physiol Scand 66:337-345

17. Sejrsen P, Tönnesen KH (1968) Inert gas diffusion method for measurement of blood flow using saturation techniques: comparison with directly measured blood flow in isolated gastrocnemius muscle of the cat. Clin Res 22:679-693

18. Lassen NA, Lindbjerg IF, Munck O (1964) Measurement of blood flow through skeletal muscle by intramuscular injection of ${ }^{133}$ xenon. Lancet 15i:686-689

19. Strindberg L, Lönnroth P (2000) Validation of an endogenous reference technique for the calibration of microdialysis catheters. Scand J Clin Lab Invest 60:205-211

20. Hickner RC, Bone D, Ungerstedt U, Jorfeldt L, Henriksson J (1994) Muscle blood flow during intermittent exercise: comparison of the microdialysis ethanol technique and ${ }^{133} \mathrm{Xe}$ clearance. Clin Sci 86:15-25
21. Bernst E, Gutman J (1974) Determination of ethanol with alcohol dehydrogenase and NAD. In: Bergmeyer HU (ed) Methods of enzymatic analysis. Academic, New York, pp 1499-1515

22. Hellmér J, Arner P, Lundin A (1989) Automatic luminometric kinetic assay of glycerol for lipolysis studies. Anal Biochem 177:132-137

23. Hallman H, Farnebo LE, Hamberg B, Jonsson G (1978) A sensitive method for determination of plasma catecholamines using liquid chromatography with electrochemical detection. Life Sci 23:1049-1052

24. Wolfe RR (1992) Radioactive and stable isotope tracers in biomedicine: principles and practice of kinetic analysis. Wiley, New York

25. Kurpad A, Khan K, Macdonald I, Elia M (1995) Haemodynamic responses in muscle and adipose tissue and whole-body metabolic responses during norepinephrine infusions in man. J Auton Nerv Syst 54:163-170

26. Arner P, Kriegholm E, Engfeldt P (1991) In vivo interactions between beta-1 and beta-2 adrenoreceptors regulate catecholamine tachyphylaxia in human adipose tissue. J Pharmacol Exp Ther 259:317-322

27. Marion-Latard F, De Glisezinksi I, Crampes F et al (2001) A single bout of exercise induces $\beta$-adrenergic desensitization in human adipose tissue. Am J Physiol Regul Integr Comp Physiol 280: R166-R173

28. Enoksson S, Nordenström J, Bolinder J, Arner P (1998) Influence of local blood flow on glycerol levels in human adipose tissue. Int J Obes 19:350-354

29. Hjemdahl P, Linde B (1983) Influence of circulating NE and Epi on adipose tissue vascular resistance and lipolysis in humans. Am J Physiol Heart Circ Physiol 245:H447-H452

30. Chang PC, Kriek E, van der Krogt JA, Blauw GJ, van Brummelen $P$ (1988) Haemodynamic effects of physiological concentrations of circulating noradrenaline in man. Clin Sci (Lond) 75:469-475

31. Clark MG, Colquhoun EQ, Rattigan S et al (1995) Vascular and endocrine control of muscle metabolism. Am J Physiol Endocrinol Metab 268:E797-E812

32. Liggett SB, Shah SD, Cryer PE (1988) Characterization of betaadrenergic receptors of human skeletal muscle obtained by needle biopsy. Am J Physiol Endocrinol Metab 254:E795-E798

33. Plourde G, Rousseau-Migneron S, Nadeau A (1993) Effect of endurance training on $\beta$-adrenergic system in three different skeletal muscles. J Appl Physiol 74:1641-1646

34. Hagström-Toft E, Qvisth V, Nennesmo I et al (2002) Marked heterogeneity of human skeletal muscle lipolysis at rest. Diabetes 51:3376-3383

35. Langfort J, Ploug T, Ihlemann J, Saldo M, Holm C, Galbo H (2000) Stimulation of hormone-sensitive lipase and its regulation by adrenaline in skeletal muscle. Biochem J 351:207-214 